\title{
Gaseous Fuel Injection Modeling using a Gaseous Sphere Injection Methodology
}

R. P. Hessel, S. M. Aceves, D. L. Flowers

March 13, 2006

International Multidimensional Engine Modeling User's Group Meeting Detroit, MI, United States

April 2, 2006 through April 6, 2006 
This document was prepared as an account of work sponsored by an agency of the United States Government. Neither the United States Government nor the University of California nor any of their employees, makes any warranty, express or implied, or assumes any legal liability or responsibility for the accuracy, completeness, or usefulness of any information, apparatus, product, or process disclosed, or represents that its use would not infringe privately owned rights. Reference herein to any specific commercial product, process, or service by trade name, trademark, manufacturer, or otherwise, does not necessarily constitute or imply its endorsement, recommendation, or favoring by the United States Government or the University of California. The views and opinions of authors expressed herein do not necessarily state or reflect those of the United States Government or the University of California, and shall not be used for advertising or product endorsement purposes. 
Title

Gaseous Fuel Injection Modeling using a Gaseous Sphere Injection Methodology

Authors

Randy P. Hessel, University of Wisconsin - Madison

Salvador M. Aceves and Daniel L. Flowers, Lawrence Livermore National

Laboratory

\begin{abstract}
The growing interest in gaseous fuels (hydrogen and natural gas) for internal combustion engines calls for the development of computer models for simulation of gaseous fuel injection, air entrainment and the ensuing combustion. This paper introduces a new method for modeling the injection and air entrainment processes for gaseous fuels. The model uses a gaseous sphere injection methodology, similar to liquid droplet injection techniques used for liquid fuel injection. In this paper, the model concept is introduced and model results are compared with correctly- and under-expanded experimental data.
\end{abstract}

\title{
INTRODUCTION
}

Natural gas and hydrogen fuels can contribute to reduce local pollution, dependence on foreign oil and greenhouse gas emissions. Used in internal combustion engines, these fuels provide clean and efficient combustion. However, carbureted or port injected engines running on gaseous fuels typically have reduced specific power, because the fuel displaces some of the intake air. Direct injection is necessary for gaseous fuel engines with high specific power [1].

Liquid fuel injection is fairly well characterized and standard engine codes (e.g. KIVA [2]) include validated injection models. Gaseous injection in engines is not as simple to model. Typically, gas injection is modeled by specifying boundary elements where a fuel inlet pressure or speed is assigned. This is difficult to implement in the code, requires remeshing for changes in injection parameters (i.e. number of injectors or direction of injection) and it may require fine grid resolution at the nozzle, increasing the computational expense.

Searching for new methodologies for analysis of gaseous fuel injection we conducted a literature survey that revealed an important concept documented by Ouellette [3, 4]. In his efforts, Ouellette found that when modeling gas jets "The momentum injection rate must be reproduced if one wants to reproduce the mixing rate," [3, pg. 189]. Accepting this to be true, it should be less critical which modeling technique is used to get the gas into the chamber, as long as the gas enters the chamber with the correct momentum rate, per Ouellette, and mass flow rate, per continuity. 
This basic concept can be advantageously used to reduce the computational effort of simulating gaseous fuel injection. Recognizing that the KIVA3V CFD code [2] has extensive capabilities for liquid fuel injection, it is a good idea to take advantage of these capabilities for gaseous fuel injection. The benefits of this approach include:

- Most coding is already in place, which reduces development time.

- A gas inlet does not have to be specified on the computational domain boundary, therefore re-meshing is not required when representing different injectors (\# of holes, hole size, hole orientation, etc.) or different flow conditions.

- A fine mesh whose cell size is some fraction of the injector hole size is not required to resolve the inflow boundary, which saves simulation run time (hole diameters can be less than $1 \mathrm{~mm}$ ).

The approach consists of injecting the gaseous fuel using the KIVA3V liquid injection model. The resulting "gaseous spheres" evaporate after a short distance, producing a gaseous jet. The gaseous spheres are fully coupled with the gas phase species with respect to energy and momentum, and therefore simulate entrainment and mixing. "Evaporation" of the gaseous spheres, i.e. their transition from being treated as distinct entities to being part of the combustion chamber gas is based on gas dynamics and empirical relations.

A detailed explanation of the coding required to successfully inject the gaseous spheres into the flow domain is beyond the scope of this paper. Instead, the general idea of the technique is given, as are preliminary results for correctlyand under-expanded jets.

\section{RESULTS}

\section{Correctly-expanded (sub-sonic) validation cases}

As with most model development work, results from simple experiments were desired for testing the model during development. Such results were obtained from experiments done by Witze $[5,6]$, where he measured penetration of an air stream injected into ambient air. Details of the experiment are given in Table 1.

\begin{tabular}{|l|l|}
\hline \multicolumn{2}{|l|}{ Table 1. Details of sub-sonic experiments by Witze $[5,6]$} \\
\hline Medium & Air injected into ambient air \\
\hline Injection pulse duration & $4 \mathrm{~ms}$, approximated by a square wave \\
\hline Nozzle diameter & $1.2 \mathrm{~mm}$ \\
\hline Injection velocities & 53 and $103.5 \mathrm{~m} / \mathrm{s}$ \\
\hline Measurement distances from orifice & $2.9,7.9,13,18.1,23.2,28.3,33.3 \mathrm{~mm}$ \\
\hline
\end{tabular}


The speed of sound at ambient conditions was approximately $343 \mathrm{~m} / \mathrm{s}$, therefore the jets were subsonic. Figure 1 shows the grid used to represent the experiments. The left image is a top view and the injector was located at the center. Although the measurements were performed in an unbounded ambient, the grid boundaries are solid, but the domain was made large enough so the solid walls did not influence the penetration results.

A square domain was used for improved computational cell quality. The mesh was refined near the injector so that typical cell dimensions were on the order of those typically used in diesel and SI grids (radial and axial cell dimensions $\sim 2 \mathrm{~mm}$ and $\sim 2.5 \mathrm{~mm}$ respectively).
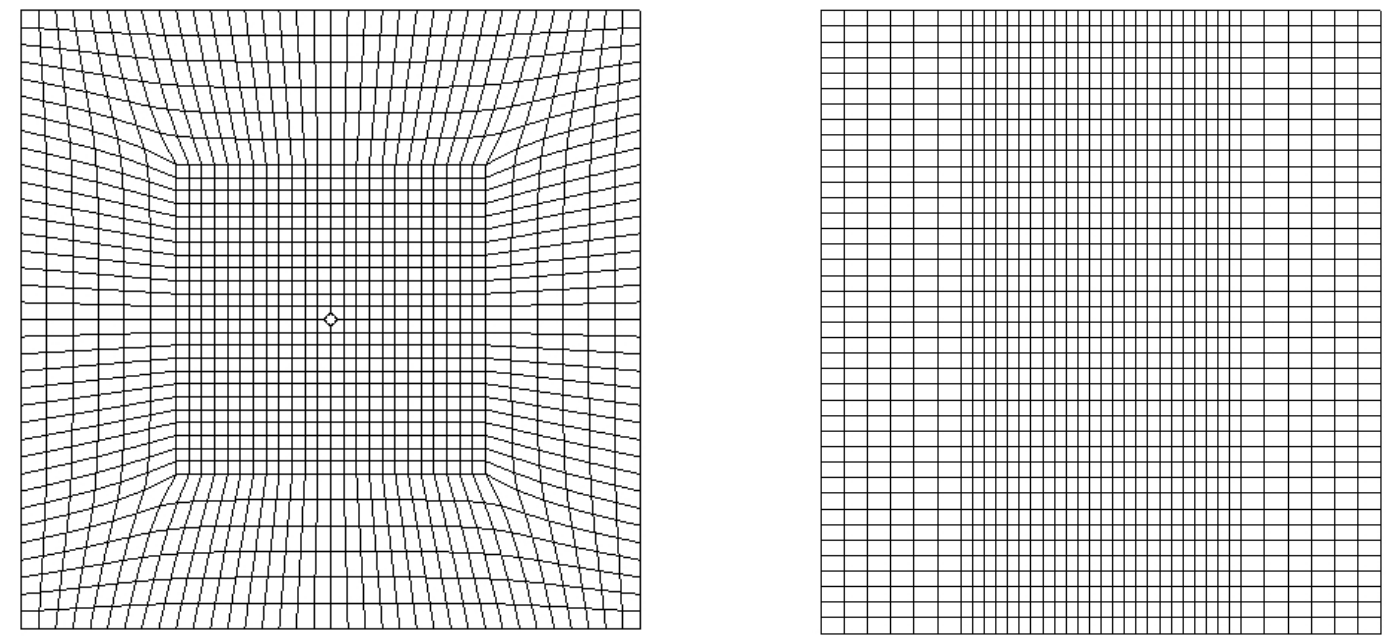

Figure 1. Grid used to present Witze experiments. Top view (left), side view (right).

Mass flow rate and momentum injection rate were matched by assuming a square wave velocity profile, assigning the injection velocity and total mass injected during the injection duration (both based on measurements), calculating density at the injector for sub-sonic jets, and assigning a gaseous sphere radius of 10 microns.

The value of 10 microns was chosen because Ouellette found that, "...for sprays with droplets of 5 and 10 microns (SMR) injected in a chamber at $1200 \mathrm{~K}$, the mixing rates of gaseous jets and sprays were much the same for equivalent nozzle momentum and mass injection rate. Furthermore, when the cone angle of the sprays and spreading angle of the gaseous jet were roughly equal, the penetration was also similar." [3, pg. 98] Therefore, if the gaseous spheres are injected at a cone angle that is representative of the physical jet, mixing and penetration should be adequately reproduced.

To ensure that the momentum rate was modeled accurately, comparisons were made between the theoretical momentum rate, the momentum rate of the jet as 
represented by the gaseous spheres and the momentum rate imparted on the ambient gas. Calculations were done with equations 1 through 3 .

Theoretical rate $=$ nozzle hole area * density * velocity * velocity

Jet rate $=$ sum over droplets $\left(\right.$ drop volume ${ }^{*}$ density * velocity $) / d t$

Ambient rate $=$ sum over cells $\left(\operatorname{sqrt}\left(r u^{* *} 2+r v^{* \star} 2+r w^{* \star} 2\right)\right) / d t$

In the above equations, density and velocity were values at the injector exit plane, drop volume was the same for each drop modeled and was based on the input value of SMR, dt was the computational time step, and ru, rv and rw were the three coordinate momentum coupling terms between the droplets and ambient gas. Representative values for each calculation are given in table 2 for the $53 \mathrm{~m} / \mathrm{s}$ injection case.

\begin{tabular}{|c|c|}
\hline Theoretical rate & 1430.8 \\
\hline Jet rate & 1430.6 \\
\hline Ambient rate & 1430.6 \\
\hline
\end{tabular}

Figure 2 compares measured to calculated velocities at the seven locations listed in table 1 . The velocity magnitudes and phasing at each measurement location are accurately captured by the model. But, the model exhibits a slower penetration rate, which could be due to over-estimates of diffusion in the radial direction, model inputs not properly representing the experiments (like the square wave injection representation), etc.
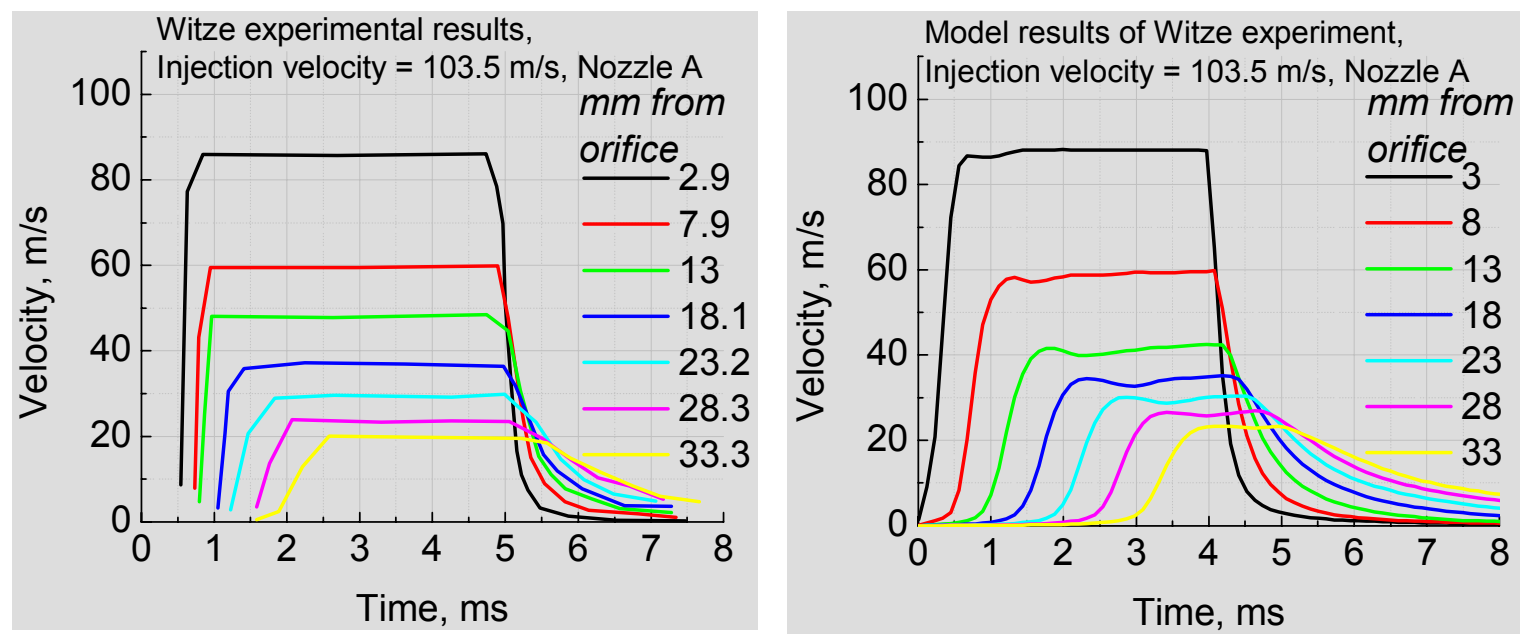

Figure 2. Measured (left) and calculated (right) velocity histories at seven locations downstream of injector. 
Since the measured data is fairly dated, it would have been challenging to track down the source of discrepancies. But, these results did show that the methodology of representing gas injection with gaseous spheres does seem to work, so under-expanded jets were tested next.

\section{$\underline{\text { Under-expanded validation cases }}$}

Ouellette $[3,4]$ ran four experiments of methane jets into air at different pressure ratios (table 3). Under these test conditions the critical pressure ratio of methane is approximately 1.8. Therefore, the first three cases of table 3 are underexpanded (pressure ratio > critical pressure ratio) and the fourth is correctlyexpanded.

\begin{tabular}{|c|c|c|c|c|c|c|c|c|c|}
\hline \multicolumn{10}{|c|}{$\begin{array}{l}\text { Table 3. Conditions for Ouellette cases of methane injection into air. } \\
\text { Subscript } 0=\text { upstream stagnation condition. Subscript } n=\text { at the nozzle } \\
\text { exit plane assuming real gas behavior and friction. Chamber pressure }=1.5 \\
\mathrm{MPa} \text { and chamber temperature }=300 \mathrm{~K} . \mathrm{P}=\text { pressure, rho=density, } \\
\mathrm{Z}=\text { compressibility factor, } M=\text { mach number, } V=\text { velocity, } P R=\text { pressure ratio. } \\
{[3, \text { pg. 55] }}\end{array}$} \\
\hline Case & $\mathrm{P}_{0}$ & $\mathrm{rho}_{0}$ & $Z_{0}$ & $M_{n}$ & $P_{n}$ & $\frac{T_{n}}{K}$ & $\mathrm{rho}_{\mathrm{n}}$ & $V_{n}$ & PR \\
\hline 1 & 8.0 & 593 & 088 & 1 & 10 & 253 & 35 & 394 & 55 \\
\hline 2 & 6.0 & 42.6 & 0.90 & 1 & 3.0 & 254 & 25 & 400 & 4.0 \\
\hline 3 & 3.7 & 25.5 & 0.94 & 1 & 1.86 & 256 & 15 & 408 & 2.5 \\
\hline 4 & 2.3 & 15.3 & 0.96 & .76 & 1.5 & 274 & 11 & 324 & 1.5 \\
\hline
\end{tabular}

Figure 3 compares modeled penetration at $1 \mathrm{~ms}$ to measurements. Model results follow observed trends and magnitudes also compare well, but the model slightly under-predicts penetration in 3 of the 4 cases.

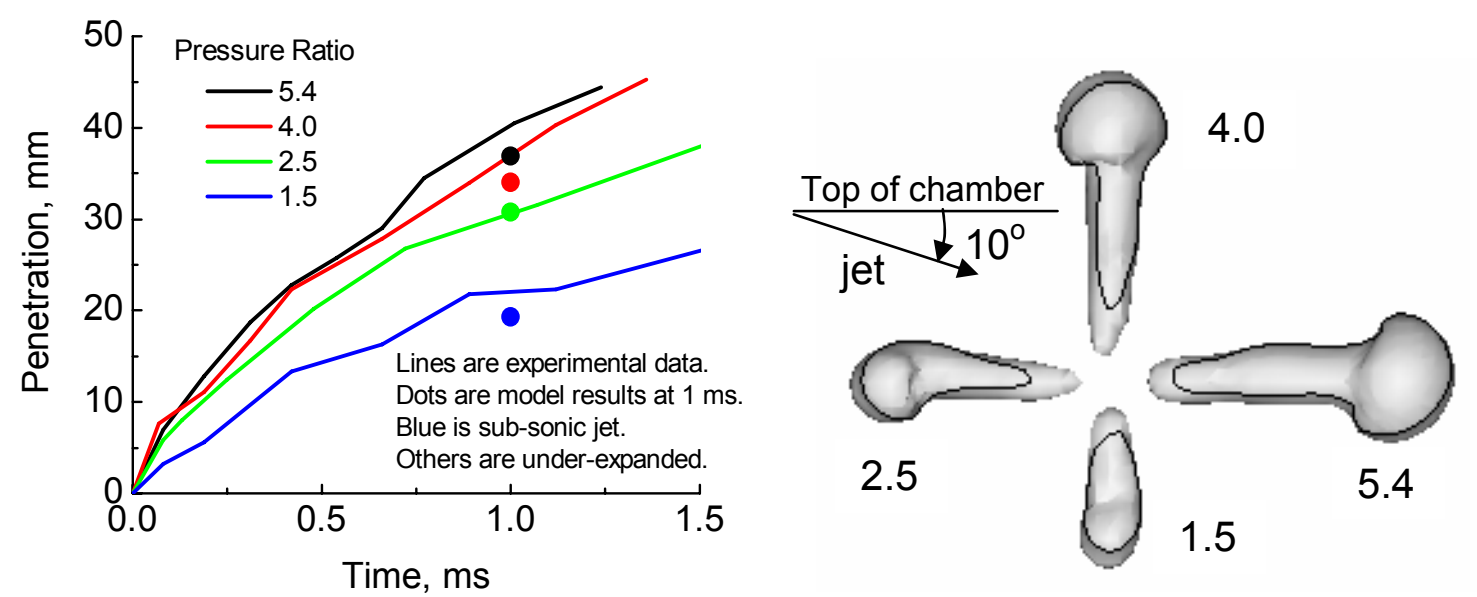

Figure 3. (left) Penetration comparison between measurements (curves) and model results at $1 \mathrm{~ms}$ (dots). (right) All four jets at $3 \mathrm{~ms}$. Top view. Black lines show intersection of iso-surfaces (3\% fuel mass fraction) with top of chamber. Jets were directed 10 degrees below top of chamber. 
It was determined in the experiments that fuel was visible in a mass fraction range between 2 and $4 \%$. The computational iso-surfaces in figure 3 show mass fractions at $3 \%$. Extracting precise penetration values from the model and the experiment is challenging, and therefore this agreement seems acceptable.

Note that all four jets were simulated in the same run to reduce the modeling effort. Jet-to-jet interaction can be observed in figure 3 as the iso-surfaces deviate from symmetry, but the interaction is deemed negligible. All jets were directed 10 degrees below horizontal.

\section{CONCLUSIONS}

A technique was developed to model gas jets using gaseous spheres, similar to those used for liquid injection. The model matched measured penetration trends for both correctly- and under-expanded jets. Modeled penetration times were close to measured values, but many cases lagged slightly. The major benefits of this technique include elimination of re-meshing for different injector conditions, or injector configurations, and grids more fine than the injector orifice are not required, because the nozzle exit flow is not resolved.

\section{ACKNOWLEDGEMENTS}

This project is funded by DOE, Office of FreedomCAR and Vehicle Technologies, Gurpreet Singh and Kevin Stork, program managers. Work performed under the auspices of the U.S. Department of Energy by University of California, Lawrence Livermore National Laboratory under Contract W-7405-ENG-48.

\section{REFERENCES}

1. Wimmer, A., Wallner, T., Ringler, J., Gerbig, F., "H2-Direct Injection - A Highly Promising Combustion Concept," SAE Paper 2005-01-0108.

2. Amsden, A. A., "KIVA-3V: A Block-Structured KIVA Program for Engines with Vertical or Canted Valves", Los Alamos National Laboratory Report No. LA-13313-MS, 1997.

3. Ouellette, Patric, "Direct Injection of Natural Gas for Diesel Engine Fueling," Ph. D. Thesis, University of British Columbia, February, 1996.

4. Ouellette, P., Hill, P. G., "Turbulent Transient Gas Injections," Journal of Fluids Engineering, Volume 122, December 2000, page 743.

5. Witze, Peter O., "The Impulsively Started Incompressible Turbulent Jet," SAND80-8617, October, 1980

6. Witze, Peter O., "Hot-Film Anemometer Measurements in a Starting Turbulent Jet," AIAA Journal, Volume 21, Number 2, February 1983, page 308. 